\title{
Salivary Glycine Is a Significant Predictor for the Attenuation of Polyp and Tumor Microenvironment Formation by Fucoxanthin in AOM/DSS Mice
}

\author{
MASARU TERASAKI ${ }^{1,2}$, SAKI MASAKA $^{1}$, CHINAMI FUKADA $^{1}$, MAYU HOUZAKI $^{1}$, TETSUYA ENDO $^{1}$, \\ TAKUJI TANAKA ${ }^{3}$, HAYATO MAEDA $^{4}$, KAZUO MIYASHITA $^{5}$ and MICHIHIRO MUTOH ${ }^{6}$ \\ ${ }^{1}$ School of Pharmaceutical Sciences, and ${ }^{2}$ Cancer Prevention Laboratories, \\ Health Sciences University of Hokkaido, Hokkaido, Japan; \\ ${ }^{3}$ Department of Diagnostic Pathology and Research Center of Diagnostic Pathology, \\ Gifu Municipal Hospital, Gifu, Japan; \\ ${ }^{4}$ Faculty of Agriculture and Life Science, Hirosaki University, Aomori, Japan; \\ ${ }^{5}$ Laboratory of Biofunctional Material Chemistry, Division of Marine Bioscience, \\ Graduate School of Fisheries Sciences, Hokkaido University, Hokkaido, Japan; \\ ${ }^{6}$ Epidemiology and Preventions Group, Center for Public Health Sciences, National Cancer Center, Tokyo, Japan
}

\begin{abstract}
Background/ Aim: A high polar xanthophyll of Fucoxanthin $(F x)$ is abundantly contained in edible brown algae, and it has chemopreventive effects in mouse cancer models, however, the underlying mechanisms of these effects are not well understood. Thus, we aimed to investigate the effects of Fx on the tumor microenvironment in cancer model mice. Materials and Methods: We investigated the effect of Fx (30 mg/kg body weight) in a variety of cell types within the tumor microenvironment of a mouse preclinical colorectal cancer model and analyzed the mouse saliva in search of predictors for cancer chemopreventive effects. Results: Fx administration significantly decreased the number of colorectal polyps and tended to decrease colonic lesions compared to
\end{abstract}

This article is freely accessible online.

Abbreviations: AOM: azoxymethane, $\alpha$-SMA: $\alpha$-Smooth muscle actin, BSA: bovine serum albumin, BW: body weight, CAFs: cancer-associated fibroblasts, CCSCs: colorectal cancer stem cells, Csps: colonospheres, DCs: dendritic cells, DSS: dextrane sodium sulfate, DW: distilled water, EMT: epithelial-mesenchymal transition, Fx: fucoxanthin, $\mathrm{FxOH}$ : fucoxanthinol, TAMs: tumorassociated macrophages, TME: tumor microenvironment.

Correspondence to: Masaru Terasaki, School of Pharmaceutical Sciences, Health Sciences University of Hokkaido, 1757 Kanazawa, Ishikari-Tobetsu, Hokkaido 061-0293, Japan. Tel: +81 133233897, e-mail: terasaki@hoku-iryo-u.ac.jp

Key Words: fucoxanthin, carotenoid, glycine, tumor microenvironment, saliva. untreated control mice. In addition, Fx administration showed significantly lower numbers of colorectal cancer stem cells-like CD44 ${ }^{\text {high}} /$ EpCAM $M^{\text {high }}$ cells, cancer-associated fibroblasts-like aSMA ${ }^{\text {high }}$ cells, tumor-associated macrophages-like and dendritic cells-like CD206 ${ }^{\text {high }}$ cells by 0.6-, 0.5- and 0.6-fold, respectively, compared to untreated control mice. Moreover, the treatment also showed significantly lower levels of salivary glycine by 0.5-fold. Conclusion: Our results suggest that salivary glycine may be a predictor representing the chemopreventive effect of $F x$ in mice.

Marine brown algae are a rich source of beneficial lipids, such as highly polar xanthophylls, polyunsaturated fatty acids and sterols, important for human health $(1,2)$. Among the brown algal lipids, a highly polar xanthophyll, fucoxanthin (Fx, Figure 1), is abundantly present in brown algae as it plays an important role in their photosynthesis and photoprotection (3). As shown in Figure 1, this xanthophyll has a unique structure, an allenic bond and a 5,6-monoepoxide. Marine brown algae, such as the Undaria pinnatifida (wakame) and the Hizikia fusiforme (hijiki), are good sources of Fx among Japanese algal foods $(1,4)$. Even in very high doses, oral consumption of Fx has been proven to be safe $(5,6)$.

Colorectal cancer (CRC) is a cancer affecting many people around the world and is the fourth most common cause of deaths from neoplasia (7). There is now substantial evidence that the consumption of fruits and vegetables rich in carotenoids is associated with CRC prevention. Therefore, many CRC preventive trials using carotenoids have been performed, however, their effects on CRC have been decided as "Limited/not conclusive" (8). As far as we know, there are 
no epidemiological studies evaluating highly polar xanthophylls such as Fx in CRC prevention. Fx is known to possess a cancer preventive potential in mouse cancer models (9-11). Our group and others have demonstrated that Fx and its metabolite, fucoxanthinol $(\mathrm{FxOH})$, suppress the growth of cancer cells in several cases (12-17), however, the mechanisms underlying the anti-cancerogenic effects of Fx and $\mathrm{FxOH}$ have remained unclear.

Recently, CRC stem cells (CCSCs) were recognized as the most important targets for cancer therapy. Self-renewal, drugresistance, metastasis, sphere formation and tumor formation are the main characteristic multiplexing properties of CCSCs (18). In addition, some of the cell surface proteins, CD44, CD133, CD166, EpCAM and LGR5, are markers associated with these CCSC features (19, 20). Among these cells, $\mathrm{CD}_{4}{ }^{+} / \mathrm{EpCAM}^{\text {high }}$-expressing cells are recognized for possessing a hallmark characteristic of the CCSC-like phenotype, such as tumorigenicity (19). Thus, the CCSC-like colonospheres (Csps) that express both CD44 and EpCAM at high levels are considered a good model for studying CCSC. These CD $44^{\text {high }} / \mathrm{EpCAM}^{\text {high }}$ colonospheres possess CCSClike properties, such as spheroid formation and tumorigenicity $(21,22)$. On the other hand, CCSCs may be affected by the tumor microenvironment (TME), stromal cells, including cancer-associated fibroblasts (CAFs) and immune cells, as well as various extracellular matrices that collectively result in enhancing the progression of the tumor and its metastasis (23-25). Despite all these, little information regarding the effect of Fx on TME is currently available.

Intracellular amino acids and carboxylic acids are used for energy metabolism, such as glycolysis, gluconeogenesis and fatty acid synthesis (26). Thus, proteins containing amino and carboxylic acids could be used as prognostic indicators representing the status of somatic cancers (27). Many such metabolite candidates have been isolated from saliva, urine, blood and tissue of CRC patients and animals (27-29). Among these biological samples, saliva may be the most promising one from the point of safety and ease of accessibility. We recently demonstrated that glycine and/or succinic acid are intracellular indicators that can predict sphere disintegration of Csps following $\mathrm{FxOH}$ treatment (30). Moreover, these molecules are also useful for predicting the time point of tumor development in Csps-xenograft mice under Fx treatment (31) however, further confirmation and investigation of prognostic metabolites present in saliva from additional cancer models is necessary. In the present study, we have investigated the suppressive effect of Fx on TME at a preclinical cancer condition in a CRC mouse model. Furthermore, we have examined the alteration of metabolite profiles in mouse saliva following Fx treatment. We suggest that Fx may be used as a prognostic marker representing TME suppression and that salivary glycine may be a predictor representing the chemopreventive effect of Fx in mice.

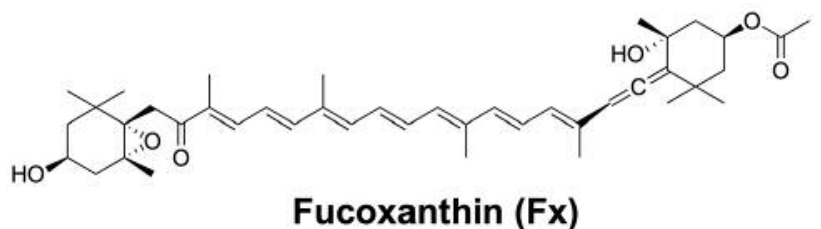

Figure 1. The Fucoxanthin (Fx) structural formula (designed using ChemDraw Professional 15.1).

\section{Materials and Methods}

Chemicals. Fx oil (5w/v\%), mixed with a palm oil $(70 \mathrm{w} / \mathrm{v} \%)$ complex with slight moisture, proteins, carbohydrates and sodium, was provided by the Oryza Oil \& Fat Chemical Co. Ltd. (Aichi, Japan). Palm oil alone $(75 \mathrm{w} / \mathrm{v} \%)$ was prepared as a control. Azoxymethane (AOM) (purity, $\geq 95 \%$ ) and dextran sodium sulfate (DSS) (M.W.: 36,000-50,000) were obtained from Wako Pure Chemicals (Osaka, Japan) and MP Biomedicals (Solon, OH, USA), respectively. Pilocarpine hydrochloride and urethane were both from Sigma-Aldrich (St. Louis, MO, USA). CD44 conjugated with Alexa Fluor 488 and CD206 conjugated Alexa Fluor 594 antibodies were purchased from BioLegend (San Diego, CA, USA). EpCAM conjugated with an APC antibody was obtained from eBioscience (San Diego, CA, USA). $\alpha$-Smooth muscle actin ( $\alpha$-SMA) antibody was purchased from Cell Signaling Technology (Danvers, MA, USA). Goat anti-rabbit IgG conjugated with Alexa Fluor 488 and ProLong Gold Antifade conjugated with 4',6-diamidino-2phenylindole (DAPI) were from Invitrogen (Carlsbad, CA, USA). All other chemicals and solvents were of analytical grade from Wako Pure Chemicals (Osaka, Japan).

Animal experiments. A detailed protocol is shown in Figure 2A. Male ICR mice were purchased at 5 weeks of age from Sankyo Labo Service (Shizuoka, Japan). All mice were randomly divided into five groups (5 mice/cage, 10 mice per group) and were maintained in a 12-hour light/dark cycle in a humidity- and temperature-controlled room. Solid food (Grade: MF, Oriental Yeast Co. Ltd.) and water were given ad libitum until sacrifice (about 10 weeks later). After a week of acclimation, mice in groups 1, 2 and 3 were treated with a single IP injection of AOM (10 mg/kg of body weight). Groups 4 and 5 were injected with saline only (IP). One week later, mice in groups 1-3 received $1.5 \mathrm{w} / \mathrm{v} \%$ DSS in drinking water for 1 week. Mice in groups 4 and 5 were given normal water during that time. Mice in groups 1, 2 and 4 were given Fx oil at 30,6 and $30 \mathrm{mg} / \mathrm{kg}$, respectively, using a stomach needle every 1 or 3 days during the final 8 weeks. Mice in groups 3 and 5 were given the equivalent volume of palm oil. Mice were anaesthetized using urethane $(1.0 \mathrm{~g} / \mathrm{kg}$, IP) for 20 minutes and their saliva $(<500 \mu \mathrm{l})$ was collected for $20 \mathrm{~min}$ following an injection of pilocarpine $(5 \mathrm{mg} / \mathrm{kg}$, SC) $40 \mathrm{~min}$ before sacrifice. Mice were sacrificed by isoflurane inhalation. Subsequently, the large bowel of each mouse was excised, was cut open longitudinally and was fixed in $10 \%$ formalin/PBS for at least 48 hours. Polyp number and size on the colonic mucosa were measured using a micrometer caliper. The polyp size $\left(\mathrm{mm}^{3}\right)$ was expressed as the formula of $a(\mathrm{~mm}) \times b^{2}(\mathrm{~mm}) / 2$ ( $a$, long range: $b$, short range). Histopathologic examinations were confirmed in hematoxylin and eosin-stained sections made from paraffin-embedded blocks prepared 
A

AOM (10 mg/kg bw)

Group no. Treatment

$1 \quad$ AOM-DSS, Fx oil $30 \mathrm{mg} / \mathrm{kg}$ bw $(n=10)$

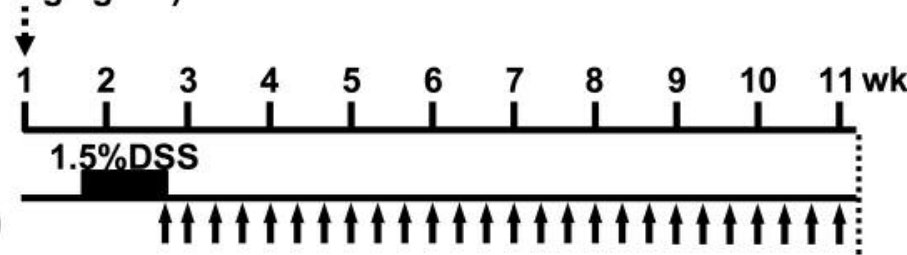

2

AOM-DSS, Fx oil $6 \mathrm{mg} / \mathrm{kg}$ bw $(n=8)$

3

AOM-DSS, control oil $(n=9)$

4

Fx oil $30 \mathrm{mg} / \mathrm{kg}$ bw $(n=10)$

5 Control oil $(n=9)$

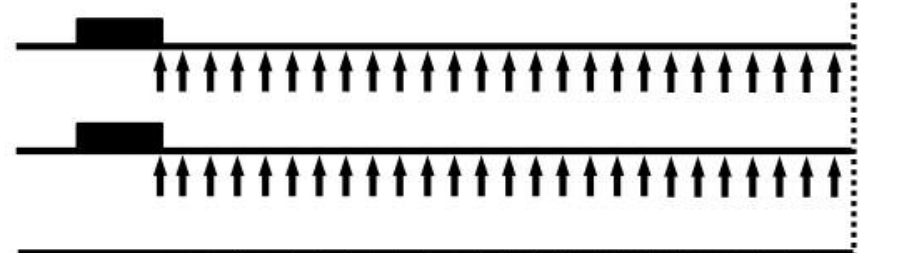

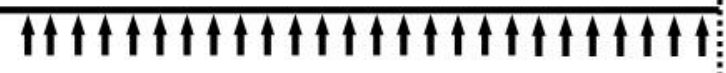

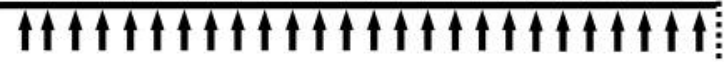
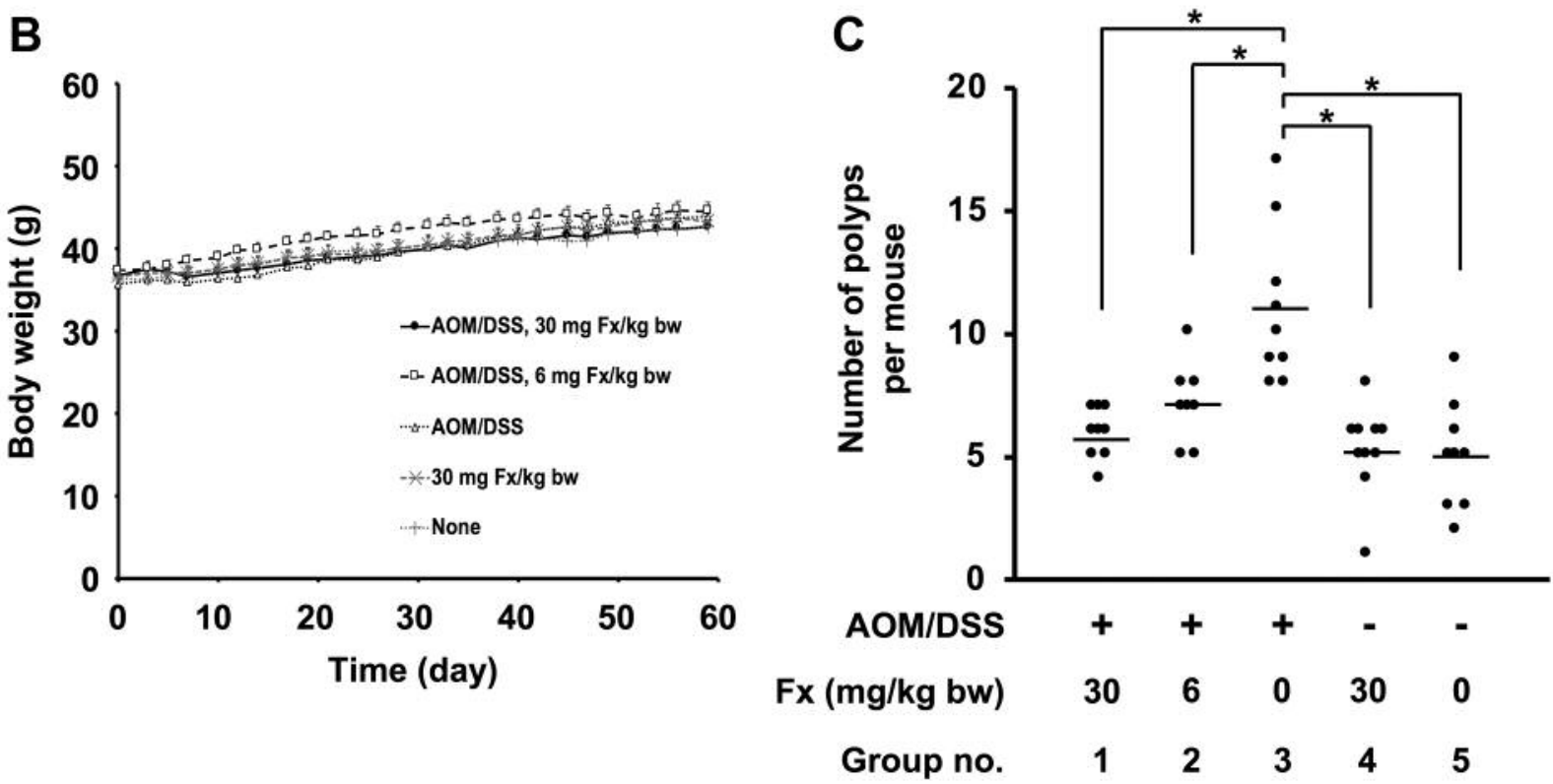

Figure 2. Effects of fucoxanthin on body weight and number of colorectal polyps in AOM/DSS mice. (A) Experimental protocol with fucoxanthin (Fx) in AOM/DSS mice. Fx oil (fucoxanthin- $5^{T M}$ ) was administrated at 30 or $6 \mathrm{mg}$ Fx/kg every 2-3 days for 8 weeks (black arrows). The control groups with or without AOM/DSS treatment was given the equivalent volume $(\mu L)$ of control oil (without $F x$ ). (B) Body weight changes from the day after DSS intake to the day of final Fx administration. (C) Polyps numbers. Means \pm SE $(n=8-10) .(*) p<0.05$ by one-way ANOVA with post-hoc Tukey-Kramer test.

by Morphotechnology (Sapporo, Japan). The experiments were performed according to the Institutional Ethics Review Committee for Animal Experimentation in the Health Sciences, University of Hokkaido, and the Guidelines for Animal Experiments in the Health Sciences, University of Hokkaido (32).

Fluorescence immunohistochemistry. Paraffin-embedded sections from the mouse colonic mucosa were stained for co-localization of CD44 together with EpCAM, or $\alpha$-SMA together with CD206, using immunofluorescence. Sections were deparaffinized and antigen-retrieval was performed with the use of $1 \mathrm{mM}$ EDTA buffer ( $\mathrm{pH} 9.0$ ) at $95^{\circ} \mathrm{C}$ for $20 \mathrm{~min}$. Sections were then washed with distilled water, PBS and tris buffer saline containing $0.1 \%$ polyoxyethylene (20) sorbitan monolaurate (TBST) and were subsequently blocked in a $5 \%$ BSA/TBST solution at room temperature for $1 \mathrm{~h}$. For detecting CCSClike cells, sections (section-A) were then incubated with the anti-CD44 antibody conjugated with Alexa Fluor 488 and the anti-EpCAM antibody conjugated with the APC antibody at a dilution of $1: 50$ in $1 \%$ BSA/TBST overnight at $4^{\circ} \mathrm{C}$. For detecting CAFs, TAMs and dendric cells (DC)-like cells, other sections (section-B) were incubated with the 

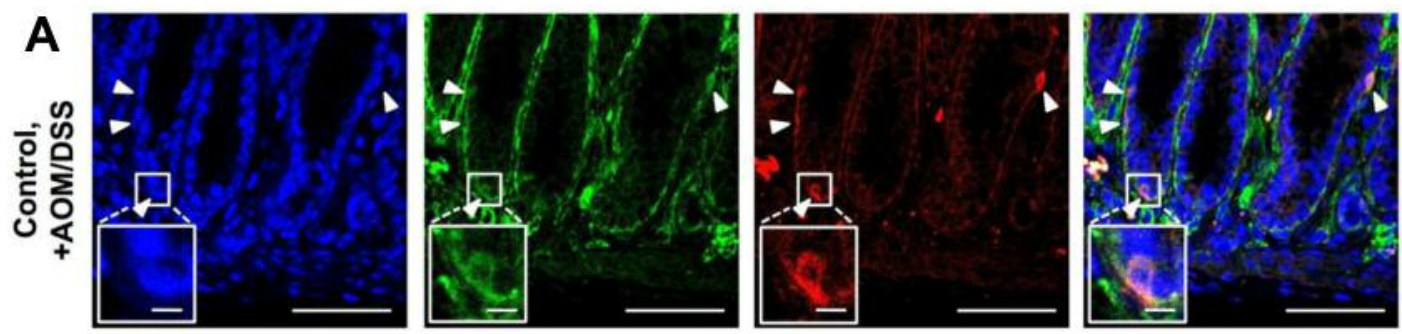

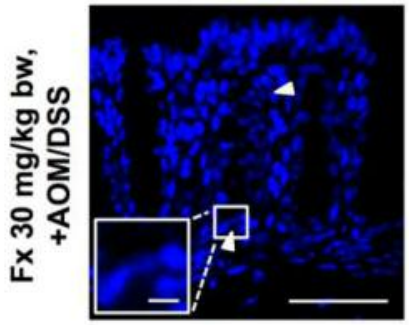

Nuclei

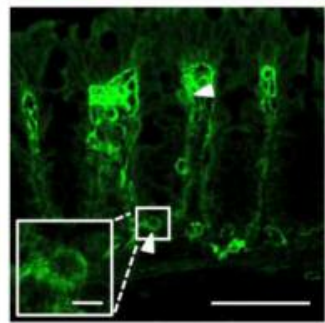

CD44

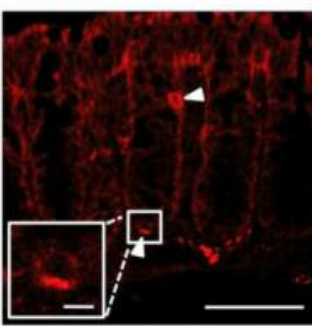

EpCAM

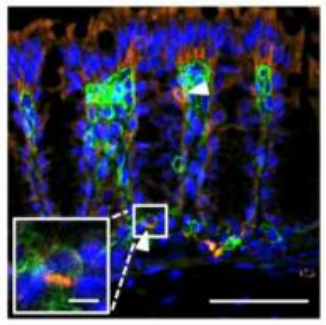

Merge

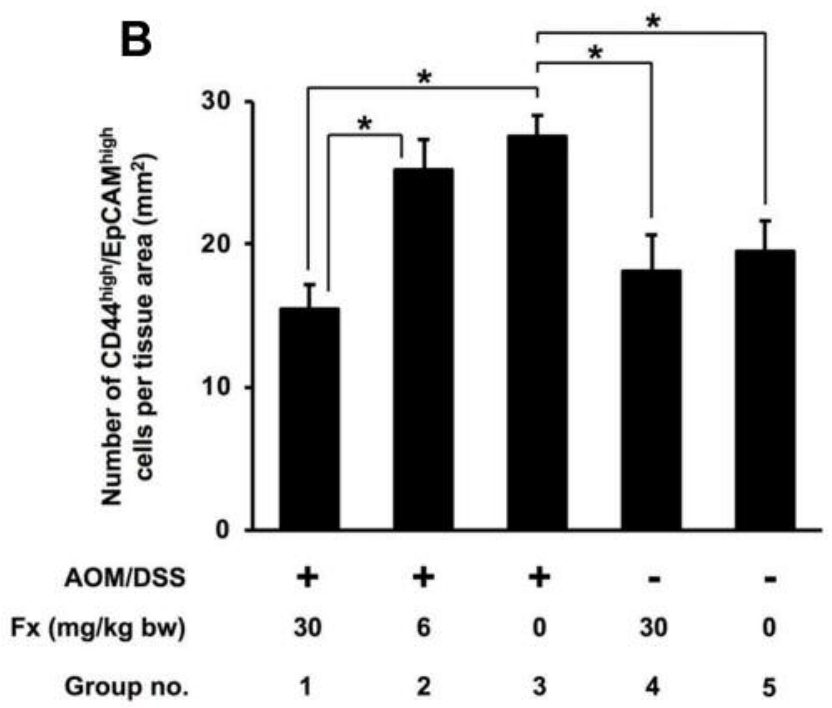

Figure 3. Detection of colorectal cancer stem cells-like CD44high/EpCAMhigh cells in AOM/DSS mice with or without Fx administration. The blocked section was co-probed with CD44 conjugated with Alexa Fluor 488 and EpCAM conjugated with APC primary antibodies. The tissue was stained with ProLong Gold Antifade reagent containing DAPI. The nuclei (blue fluorescence), CD44 (green fluorescence), and EpCAM (red fluorescence) were observed by confocal microscopy. (A) Arrow heads show cells having high expression of CD44 and EpCAM: CD44high/EpCAM high cells. Long and short bars are 50 and $5 \mu \mathrm{m}$, respectively. (B) The number of CD44high/EpCAMhigh cells per tissue area (mm $\left.{ }^{2}\right)$ was counted under confocal microscopy. Means \pm SE $(n=6)$. $(*) p<0.05$ by one-way ANOVA with post-hoc Tukey-Kramer test.

a-SMA primary antibody diluted 1:50 in 1\%BSA/TBST overnight at $4^{\circ} \mathrm{C}$, washed with TBST, and were then incubated with a goat anti-rabbit IgG conjugated with Alexa Fluor 488 at a dilution of 1:100 in PBST for 1 hour at room temperature and in the dark. Section-B slides were then probed with anti-CD206 conjugated with Alexa Fluor 594 antibody overnight at $4^{\circ} \mathrm{C}$. Both sections-A and -B were washed with TBST and PBS and were finally stained with ProLong Gold Antifade reagent with DAPI. Immunofluorescence imaging was performed using a Nikon TE2000 confocal microscope equipped with an EZ-C1 software (Nikon, Melville, NY, USA). The number of CD44high/EpCAM ${ }^{\text {high }}, \alpha$-SMA ${ }^{\text {high }}$ and CD206 high cells was evaluated per set tissue area $\left(\mathrm{mm}^{2}\right)$.
Gas Chromatography-Mass Spectrometry. A $100 \mu \mathrm{l}$ aliquot of collected saliva was dispensed, and $0.05 \mu \mathrm{g}$ of 2-isopropylmalic acid (Sigma-Aldrich, St. Louis, MA, USA) was spiked as an internal standard. The aqueous components were extracted with $0.5 \mathrm{ml}$ of $\mathrm{CH}_{3} \mathrm{OH} / \mathrm{CHCl}_{3} / \mathrm{DW}(2.5: 1: 1, \mathrm{v} / \mathrm{v} / \mathrm{v})$, centrifuged at $16,000 \mathrm{~g}$ for 5 min and the upper phase was washed with $0.5 \mathrm{ml}$ of DW. The upper extracts were dried and were subsequently derivatized using methoxyamine hydrochloride and $N$-methyl- $N$ (trimethylsilyl)trifluoroacetate. GC-MS was achieved with the use of a GCMSQP5000 spectrometer (Shimadzu, Kyoto, Japan) equipped with a Rxi5ms column (30 mx0.25 mm i.d., film thickness: $0.25 \mu \mathrm{m}$, RESTEK 

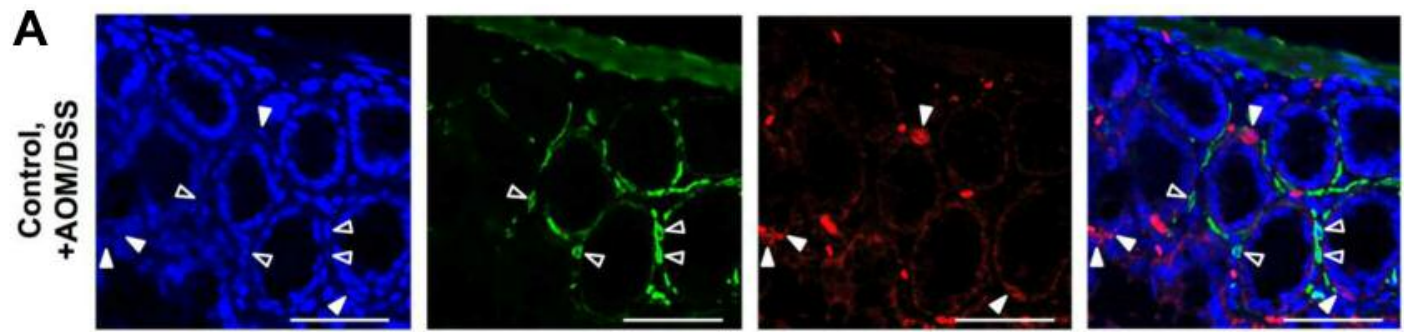

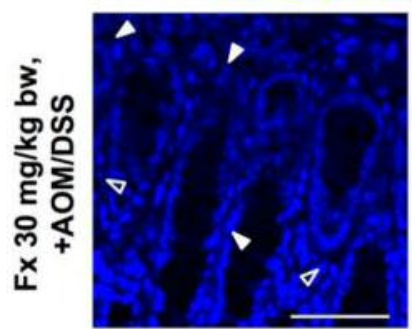

Nuclei

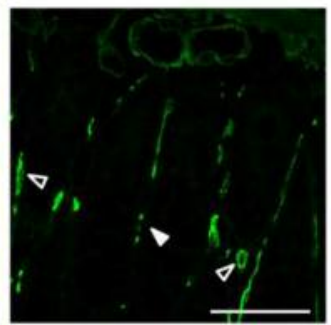

aSMA

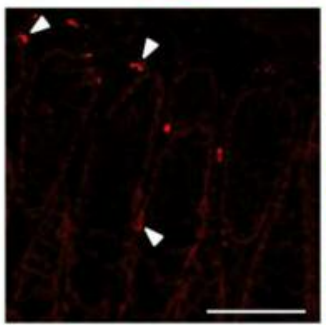

CD206

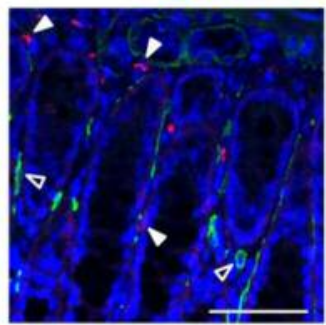

Merge
B

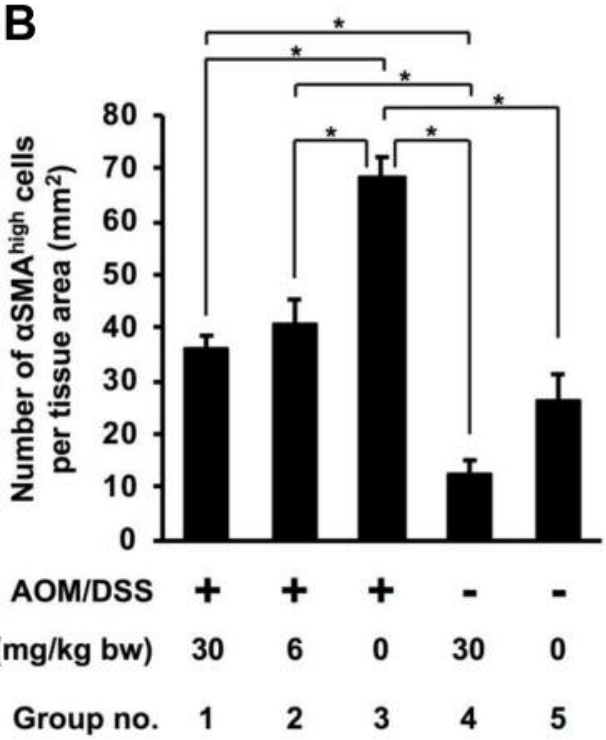

C

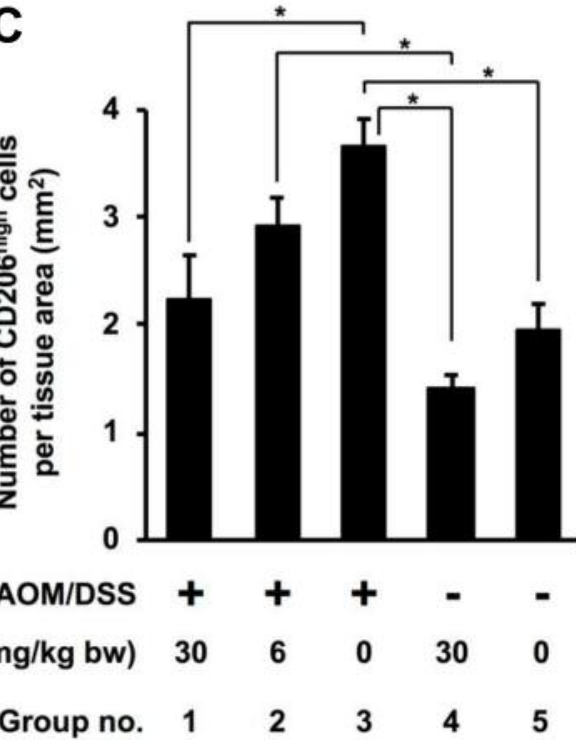

Figure 4. Detection of cancer-associated fibroblasts cells-like $\alpha S M A^{\text {high }}$ cells, and tumor-associated macrophages- and dendritic cells-like CD206 high cells in AOM/DSS mice with or without Fx administration. The nuclei (blue fluorescence), $\alpha$-SMA (green fluorescence), and CD206 (red fluorescence) were observed under a confocal microscope. (A) Arrow heads show cells having high expression of $\alpha S M A$ ( $\alpha S M A^{\text {high }}$ cells, open arrowheads) and

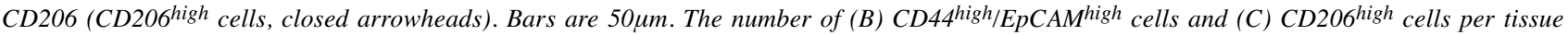
area $\left(\mathrm{mm}^{2}\right)$ were counted under the confocal microscope. Means \pm SE $(n=6) .(*) p<0.05$ by one-way ANOVA with post-hoc Tukey-Kramer test.

Co. Ltd., GmbH, Bad Homburg, Germany). Samples (1 $\mu$ l) were injected with helium $(0.5 \mathrm{ml} / \mathrm{min})$ as the carrier gas, with a split ratio of $1: 3$. Column temperature program was as follows: i) $80^{\circ} \mathrm{C}$ for 2 min, ii) $80-330^{\circ} \mathrm{C}$ for $4 \mathrm{~min}$, and iii) $330^{\circ} \mathrm{C}$ for $8 \mathrm{~min}$. The ion source and interface temperatures were 230 and $250^{\circ} \mathrm{C}$, respectively. The identification of the low-molecular weight metabolites was confirmed by comparing them to authentic standards. Metabolite contents were expressed in picomoles (pmol) per $100 \mu \mathrm{l}$ of saliva.

Statistical analyses. All the results are expressed as mean $\pm \mathrm{SE}$ values. Significant differences for multiple comparison tests were performed by one-way ANOVA followed by a Tukey-Kramer post-hoc test. Differences were considered statistically significant at $p<0.05$.

\section{Results}

Suppression of colorectal polyp formation in AOM/DSS mice by $F x$. No differences in clinical signs and food intake were observed by the administration of Fx to the preclinical cancer AOM/DSS mice for 8 weeks. There were no significant differences in the body weight of mice among the five 
groups during the Fx treatment period (Figure 2B). Interestingly, the number of polyps in Fx-treated mice (groups 1 and 2) was significantly lower compared to the polyps of mice in group 3 ( $p=0.000021, p=0.003832$, respectively), and was comparable to the number of polyps in groups 4 and 5: i) group 1: $5.7 \pm 0.4$, ii) group 2: $7.1 \pm 0.6$,

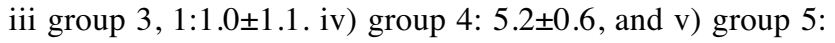
$5.0 \pm 0.7$ polyps (Figure 2C). No significant difference was observed in the polyp size among the five groups (Table I). Pathology examination revealed that the incidence and/or multiplicity of mucosal ulcer, dysplastic crypts, adenoma and adenocarcinoma tended to be lower when Fx was administered at 30 (group 1) and/or at 6 (group 2) $\mathrm{mg} / \mathrm{kg}$, compared to the control mice (group 3) (Table II).

Effect of Fx on colorectal cancer stem cell-like cells in AOM/DSS mice. We evaluated the number of CCSC-like $\mathrm{CD} 44^{\text {high }} / \mathrm{EpCAM}^{\text {high }}$ cells in colonic mucosal crypts for AOM/DSS mice by fluorescent immunohistochemistry (Figure 3A and B). CCSC-like cells showed a remarkably strong fluorescence for both CD44 and EpCAM proteins $\left(\mathrm{CD} 44^{\text {high }} / \mathrm{EpCAM}^{\text {high }}\right)$ in the colonic crypt cells. The $\mathrm{CD} 44^{\text {high }} / \mathrm{EpCAM}^{\text {high }}$ cells in group-1 were significantly lower (0.6-fold, $p=0.001087$ ) compared to those cells in control AOM/DSS mice (group 3), and to the cells from groups 4 and 5. A significant difference in the number of $\mathrm{CD} 44^{\text {high/ }}$ EpCAM $^{\text {high }}$ cells was observed between groups 1 and 2 $(p=0.017064)$, but none was found between groups 2 and 3 .

Effect of Fx on cancer-associated fibroblasts-, tumorassociated macrophage- and dendritic cell-like cells in AOM/DSS mice. Next, we investigated the accumulation of CAF-like $\alpha$-SMA ${ }^{\text {high }}$ cells, and TAM- and DC-like CD206 $6^{\text {high }}$ cells in the colonic mucosal stroma of AOM/DSS mice (Figures 4A-C). CAF-like cells showed a remarkably strong fluorescence of $\alpha$-SMA ( $\alpha$-SMA $\left.{ }^{\text {high }}\right)$. Inflammatory tumor-associated macrophages (TAMs) or dendritic cells (DC)-like cells with a remarkably strong fluorescence of the CD206 protein $\left(C D 206^{\text {high }}\right)$ were seen surrounding the colonic crypts. The $\alpha$-SMA ${ }^{\text {high }}$ and CD206 $6^{\text {high }}$ cells existed in the surrounding area of the mucosal crypts (Figure 4A). The $\alpha$-SMA ${ }^{\text {high }}$ cells in groups 1 and 2 that were treated with Fx, were significantly lower by 0.5 - and 0.6 -fold, respectively, compared to those in group 3 of the control AOM/DSS mice ( $p=0.000169, p=0.000920$, respectively). The number of $\alpha$-SMA ${ }^{\text {high }}$ cells in groups 1 and 2 was, however, significantly higher compared to cells in group 4 ( $p=0.000910, p=0.000127$, respectively). The CD206 ${ }^{\text {high }}$ cells treated with $30 \mathrm{mg} / \mathrm{kg}$ of $\mathrm{FX}$ in group 1 were significantly decreased by 0.6 -fold compared to those cells in the control AOM/DSS mice (group 3) ( $p=0.010422)$, whereas no difference in cell numbers was found between groups 4 and 5. Moreover, significant difference was
Table I. Polyp size of AOM/DSS mice with fucoxanthin $(F x)$.

\begin{tabular}{lcc}
\hline Group no. & Treatment & Polyp size $\left(\mathrm{mm}^{3}\right)^{\mathrm{a}}$ \\
\hline 1 & AOM-DSS, Fx 30 mg/kg bw & $1.4 \pm 0.2$ \\
2 & AOM-DSS, Fx 6 mg/kg bw & $1.4 \pm 0.2$ \\
3 & AOM-DSS & $1.0 \pm 0.2$ \\
4 & Fx 30 mg/kg bw & $1.0 \pm 0.1$ \\
5 & None & $1.1 \pm 0.2$ \\
\hline
\end{tabular}

${ }^{a}$ Mean \pm SE $(n=45-99)$. Data showed no significant difference using oneway ANOVA with a Tukey-kramer post-hoc test.

observed between groups 2 and $4(p=0.010799)$, but not between groups 2 and 3 .

Changes of salivary metabolites in AOM/DSS mice by Fx. Quantitative data of the salivary metabolite profiles in FXadministrated AOM/DSS mice were examined by GC-MS (Figure 5). Of the nine metabolites detected, only glycine was significantly lower in the Fx-treated mice from groups 1 and 2 compared to group 3 control mice $(p=0.020104$, $p=0.043912$, respectively), while it was at similar levels for the mice in groups 4 and 5: i) group 1: $39.3 \pm 3.6$, ii) group 2: $43.4 \pm 2.6$, iii) group 3: $76.0 \pm 11.6$, iv) group 4: 52.4 \pm 5.1 , v) group 5: $52.0 \pm 9.3$ pmol.

\section{Discussion}

Our results suggest that $\mathrm{Fx}$ administration suppresses the formation of colonic polyps and TME in AOM/DSS mice during a cancer preclinical condition. In addition, glycine was found to be a prognostic indicator representing the chemopreventive efficacy of Fx in this cancer mouse model. This is the first report suggesting a salivary indicator related to TME attenuation in cancer mouse models treated with Fx. In this study, many CCSC-like CD44 ${ }^{\text {high}} / \mathrm{EpCAM}^{\text {high }}$ cells developed in the colorectal crypts of the AOM/DSS control mice that received no treatment (group 3), but were significantly lower in the same mouse model treated with $30 \mathrm{mg} / \mathrm{kg}$ Fx (group 1).

As the formation of TME could change the progression of tumorigenesis, we evaluated how the treatment with Fx may affect the number of CAF-, TAM- and DC-like cells. Accumulating evidence has demonstrated that CAFs are largely composed of elements of TME and facilitate cancer stemness, tumor growth, invasion, metastasis, epithelial-mesenchymal transition (EMT), angiogenesis, as well as alterations in the extracellular matrix, tumor immunity and TME metabolome (33-35). CAFs are characterized by high levels of $\alpha$-SMA that is distinctive for the myofibroblast differentiation phenotype and is regarded as a prognostic marker of human CRC $(36,37)$. We found that Fx treatment at both doses of 30 and $6 \mathrm{mg} / \mathrm{kg}$ was 

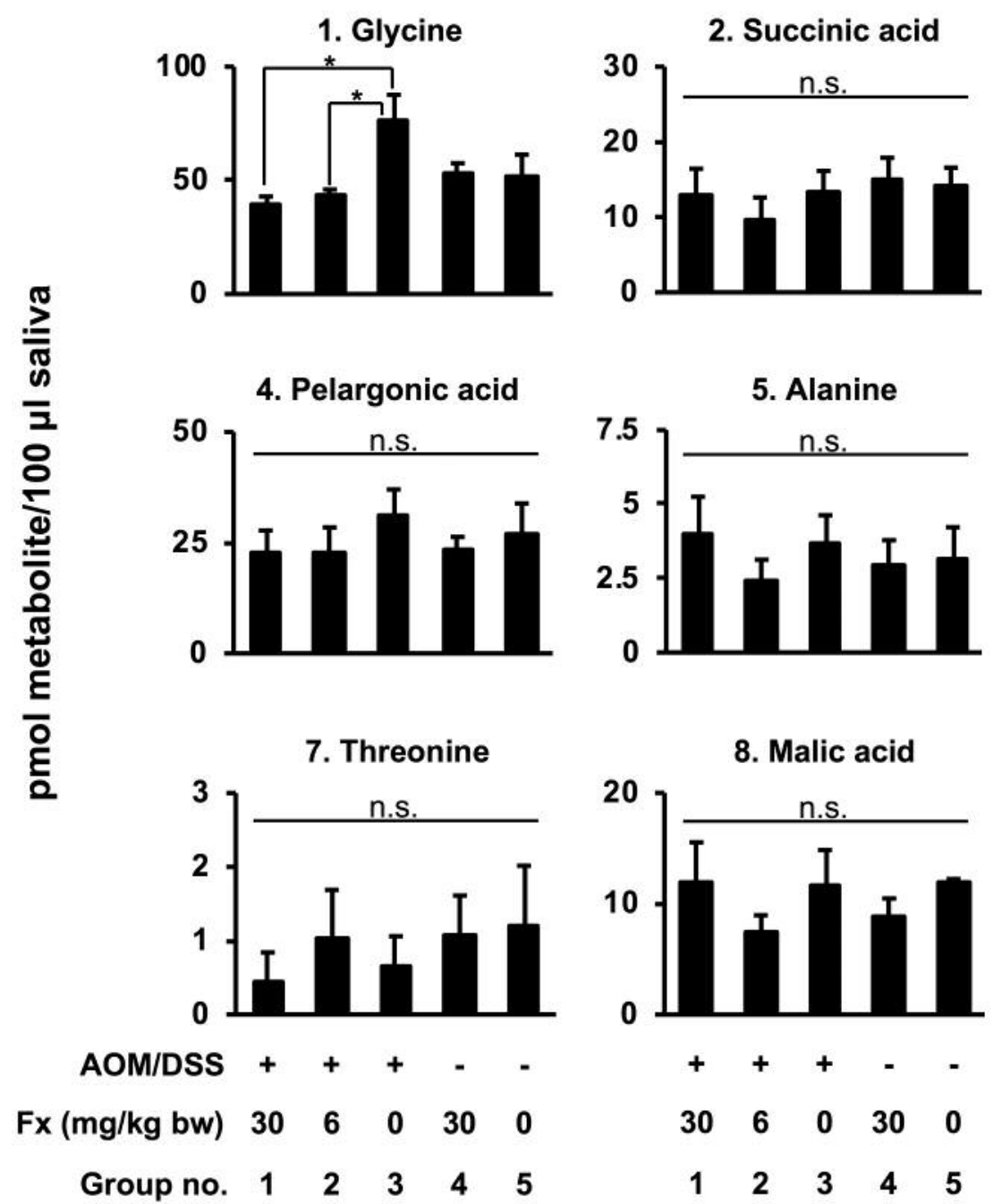

\section{Fumaric acid}
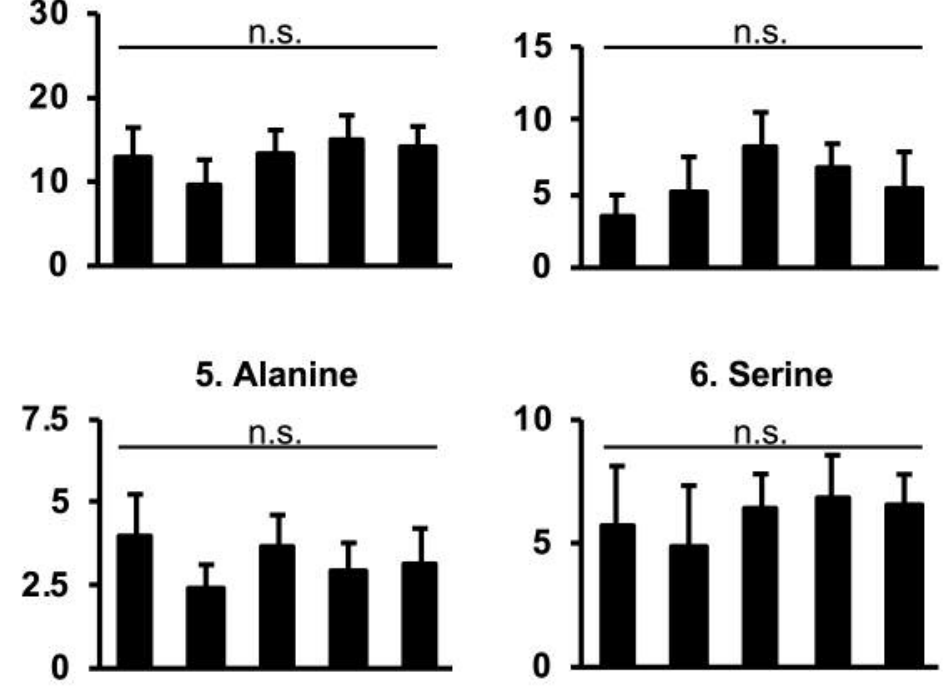

Figure 5. Effects of Fx on salivary metabolite content in AOM/DSS mice. Mouse saliva was collected after pilocarpine injection under anesthesia, and metabolites were analyzed by GC-MS. Mean \pm SE $(n=6) .(*) p<0.05$ by one-way ANOVA with post-hoc Tukey-Kramer test.

Table II. Incidence (\%) and multiplicity (no. of lesion/colon) of colonic lesions. All data of multiplicity are shown as a Mean \pm SE ( $n=5$ ).

\begin{tabular}{lcccccc}
\hline Group no. & Treatment & Mucosal ulcer & Dysplastic crypts & Adenoma & Adenocarcinoma & Total tumors \\
\hline 1 & AOM-DSS, Fx 30 mg/kg bw & $20 \% 0.2 \pm 0.2^{\mathrm{b}}$ & $20 \% 0.2 \pm 0.2$ & $0 \%$ & $0 \%$ & $0 \%$ \\
2 & AOM-DSS, Fx 6 mg/kg bw & $20 \% 0.2 \pm 0.2$ & $20 \% 0.2 \pm 0.2$ & $0 \%$ & $0 \%$ & $20 \% 0.4 \pm 0.4$ \\
3 & AOM-DSS & $20 \% 0.4 \pm 0.4$ & $60 \% 1.6 \pm 1.1$ & $20 \% 0.4 \pm 0.4$ & $20 \% 0.8 \pm 0.8$ \\
4 & Fx 30 mg/kg bw & $20 \% 0.2 \pm 0.2$ & $0 \%$ & $0 \%$ & $0 \%$ & $0 \%$ \\
5 & None & $0 \%$ & $0 \%$ & $0 \%$ & $0 \%$ \\
\hline
\end{tabular}

aIt was detected as mostly healed. bMean \pm SE (no 5). Data showed no significant differences using the Fisher's exact probability test against the AOM-DSS control mice and for one-way ANOVA with a Tukey-Kramer post-hoc test.

accompanied by an accumulation of CAF-like $\alpha$-SMA ${ }^{\text {high }}$ cells in the mucosal stroma of neighboring colonic crypts to a similar degree. Other groups have previously indicated that $\alpha$-SMApositive CAFs spread to adjacent CRC tissue of AOM/DSS- induced and/or in genetically-modified mouse cancer models, as compared to control mice $(38,39)$. Targeting cellular components of CAFs can contribute to the reduction of tumor development and CCSC function. For example, IKK $\beta$, a 
potential activator of a pro-tumorigenic form of NF-kB, has been shown to originate from CAFs in colorectal cancer mouse models (38). Oral administration of regorafenib, a multikinase inhibitor, has been found to attenuate the interaction between human KM125M CRC cells and stromal cells (including CAFs), and inhibit the metastasis of CRC cells, angiogenesis and lymphangiogenesis in nude mice (40). Both genetic and pharmacological inhibitions of a fibroblast activation protein (FAP), which can be used as a cell surface CAF marker, suppressed tumor growth derived from mouse CT26 CRC cells in an allogeneic transplant mouse model (41). Treatment by a vitamin A analogue of retinoic acid appears to inhibit the migration and EMT of pancreatic cancer cells through low levels of secreted IL-6 from CAFs (42). Curcumin, a phenol contained in turmeric, disrupts the cell-cell interactions of CCSCs-like Csps from human HCT116 CRC cells and normal human MRC-5 fibroblast cells mediated by the suppression of the TGF- $\beta 3, \mathrm{NFKB}$, matrix metalloprotease-13, CCSC cell surface markers and of EMT-related molecules (43).

In this study, we have also detected TAM- and DC-like cells, using a cell surface marker of CD206 in mouse colonic mucosa, which is commonly overexpressed in TAMs and DCs $(44,45)$. TAMs, a type of M2-phenotype macrophage, and DCs, are both pivotal components of TME and promote cancer initiation, tumor development, invasion, inflammation, angiogenesis, while they can cause immunosuppression (24, $25,44,46)$. CRC initiation and development are elicited by many molecular regulations from TAMs and DCs via their chemokines, cytokines, modifications of extracellular matrix $(24,25)$. In this study, Fx administration, particularly at the high dose of $30 \mathrm{mg} / \mathrm{kg}$ had a suppressive effect on the number of TAMs- and DCs-like CD206 ${ }^{\text {high }}$ cells present in the mucosal stroma of the mice.

Limited molecular information regarding TAMs and DCs is currently available for the Fx-treated TME. A synthetic retinoid derivative, fenretinide, suppresses TAMs polarization involved in CRC progression through the inhibition of STAT6 phosphorylation, and thus prevents CRC in $A p c^{\mathrm{min} /+}$ mice (47). Isoliquiritigenin, a flavonoid from licorice, has been found to also suppress CRC development in AOM/DSS mice with the attenuation of TAMs polarization mediating the downregulation of PGE2 and IL-6 (48). Finally, STAT3-inactivated DCs promote anti-tumor immune responses and suppress tumor growth in an allogeneic mouse model injected with mouse MC38 CRC cells, compared to mice injected with control DCs (49).

Many salivary metabolites obtained from oral, breast and pancreatic cancer patients are shown to be much higher as compared to healthy individuals (50), however, to date, there is little evidence on the role of these metabolites isolated from the saliva of cancer models. Our previous studies suggest that the low levels of glycine in the tumor and the high levels of glycine, glutamic acid and succinic acid in the saliva, could be metabolite indicators predicting a delay in the tumor onset in Csps-xenograft mice treated with Fx (31). In the present study only glycine, among the nine metabolites identified in the saliva of AOM/DSS mice, was significantly lower when mice were treated with Fx. Thus, salivary glycine could be a candidate marker indicating the chemopreventive efficacy of Fx. It is possible that the changes observed in salivary metabolites may be related to the dose and the duration of Fx administration, the saliva sampling method, the mouse strain, and the cancer model.

In summary, we found that Fx significantly suppresses the number of colorectal polyps and the formation of TME, as evaluated by the different numbers of CCSCs-, CAFs-, TAMs- and DCs-like cells in AOM/DSS mice at a cancer preclinical condition, with or without treatment with $\mathrm{Fx}$, along with low levels of salivary glycine. Our results imply that salivary glycine may be a predictor associated with the chemopreventive efficacy of Fx in this cancer model. Further studies are needed to confirm the diagnostic usefulness of salivary glycine and possibly other such metabolites for cancer chemoprevention in additional cancer animal models following their treatment with Fx

\section{Conflicts of Interest}

The Authors declare no competing financial interest.

\section{Authors Contributions}

M. Terasaki conceived and designed the study. M. Terasaki, S. Masaka, C. Fukada, M. Houzaki and T. Tanaka performed the experiments. M. Terasaki and M. Mutoh wrote the paper. T. Endo, $\mathrm{H}$. Maeda and K. Miyashita reviewed the edited the manuscript. All authors read and approved the manuscript and agree to be accountable for all aspects of the research in ensuring that the accuracy or integrity of any part of the work are appropriately investigated and resolved.

\section{Acknowledgements}

This work was supported in part by the Japan Society for the Promotion of Science KAKENHI (no. 16K07880).

\section{References}

1 Terasaki M, Hirose A, Narayan B, Baba Y, Kawagoe C, Yasui H, Saga N, Hosokawa M and Miyashita K: Evaluation of recoverable functional lipid components of several brown seaweeds (phaeophyta) from Japan with special reference to fucoxanthin and fucosterol contents. J Phycol 45(4): 974-980, 2009. PMID: 27034228 doi: 10.1111/j.1529-8817.2009.00706.x

2 Miyashita K, Nishikawa S, Beppu F, Tsukui T, Abe M and Hosokawa M: The allenic carotenoid fucoxanthin, a novel marine nutraceutical from brown seaweeds. J Sci Food Agric 91: 1166-1174, 2011. PMID: 21433011 doi: 10.1002/jsfa.4353 
3 Mikami K and Hosokawa M: Biosynthetic pathway and health benefits of fucoxanthin, an algae-specific xanthophyll in brown seaweeds. Int J Mol Sci 14: 13763-13781, 2013. PMID: 23820585 doi: $10.3390 /$ ijms 140713763

4 Terasaki M, Narayan B, Kamogawa H, Nomura M, Stephen NM, Kawagoe C, Hosokawa M and Miyashita K: Carotenoid profile of edible Japanese seaweeds: an improved HPLC method for separation of major carotenoids. J Aquatic Food Prod Tech 21: 468479, 2012. doi: https://doi.org/10.1080/10498850.2011. 610025

5 Beppu F, Niwano Y, Tsukui T, Hosokawa M and Miyashita K: Single and repeated oral dose toxicity study of fucoxanthin (FX), a marine carotenoid, in mice. J Toxicol Sci 34: 501-510, 2009. PMID: 19797858

6 Iio K, Okada Y and Ishikura M: Single and 13-week oral toxicity study of fucoxanthin oil from microalgae in rats. Shokuhin Eiseigaku Zasshi 52: 183-189, 2011. PMID: 21720124

7 Ferlay J, Soerjomataram I, Dikshit R, Eser S, Mathers C, Rebelo M, Parkin DM, Forman D and Bray F: Cancer incidence and mortality worldwide: source, methods and major patterns in GLOBOCAN 2012. Int J Cancer 136: E359-E386, 2015. PMID: 25220842 doi: $10.1002 / \mathrm{ijc} .29210$

8 World Cancer Research Fund/American Institute for Cancer Research, Food, Nutrition, Physical Activity and the Prevention of Cancer: a Global Perspective. AICR 280-288, 2007. ISBN: 978-0-9722522-2-5

9 Kim JM, Araki S, Kim DJ, Park CB, Takasuka N, BabaToriyama H, Ota T, Nir Z, Khachik F, Shimidzu N, Tanaka Y, Osawa T, Uraji T, Murakoshi M, Nishino $H$ and Tsuda $H$ : Chemopreventive effects of carotenoids and curcumins on mouse colon carcinogenesis after 1,2-dimethylhydrazine initiation. Carcinogenesis 19: 81-85, 1998. PMID: 9472697

10 Nishino H, Murakoshi M, Tokuda H and Satomi Y: Cancer prevention by carotenoids. Arch Biochem Biophys 483: 165-168, 2009. PMID: 18848517 doi: 10.1016/j.abb.2008.09.011

11 Mei CH, Zhou SC, Zhu L, Ming JX, Zeng FD and Xu R: Antitumor effects of Laminaria extract fucoxanthin on lung cancer. Mar Drugs 15: 39-50, 2017. PMID: 28212270 doi: 10.3390/md15020039

12 Takahashi K, Hosokawa M, Kasajima H, Hatanaka K, Kudo K, Shimoyama N and Miyashita K: Anticancer effects of fucoxanthin and fucoxanthinol on colorectal cancer cell lines and colorectal cancer tissues. Oncol Lett 10: 1463-1467, 2015. PMID: 26622691 doi: 10.3892/ol.2015.3380

13 Terasaki M, Maeda H, Miyashita K and Mutoh M: Induction of anoikis in human colorectal cancer cells by fucoxanthinol. Nutr Cancer 69: 1043-1052, 2017. PMID: 28990814 doi: 10.1080/ 01635581.2017 .1339814

14 Das SK, Hashimoto T and Kanazawa K: Growth inhibition of human hepatic carcinoma HepG2 cells by fucoxanthin is associated with down-regulation of cyclin D. Biochim Biophys Acta 1780: 743-749, 2008. PMID: 18230364 doi: 10.1016/ j.bbagen.2008.01.003

15 Jin Y, Qiu S, Shao N and Zheng J: Fucoxanthin and tumor necrosis factor-related apoptosis-inducing ligand (TRAIL) synergistically promotes apoptosis of human cervical cancer cells by targeting PI3K/Akt/NF-kB signaling pathway. Med Sci Monit 24: 1-18, 2018. PMID: 29291370

$16 \mathrm{Yu}$ RX, Yu RT and Liu Z: Inhibition of two gastric cancer cell lines induced by fucoxanthin involves downregulation of Mcl-1 and STAT3. Hum Cell 31: 50-63, 2018. PMID: 29110251 doi: $10.1007 / \mathrm{s} 13577-017-0188-4$
17 Kotake-Nara E, Terasaki M and Nagao A: Characterization of apoptosis induced by fucoxanthin in human promyelocytic leukemia cells. Biosci Biotechnol Biochem 69: 224-227, 2005. PMID: 15665492 doi: 10.1271/bbb.69.224

18 Testa U and Pelosi E: Castelli, G. Colorectal cancer: genetic abnormalities, tumor progression, tumor heterogeneity, clonal evolution and tumor-initiating cells. Med Sci 6: 31-143, 2018. PMID: 29652830 doi: 10.3390/medsci6020031

19 Dalerba P, Dylla SJ, Park IK, Liu R, Wang X, Cho RW, Hoey T, Gurney A, Huang EH, Simeone DM, Shelton AA, Parmiani G, Castelli $\mathrm{C}$ and Clarke MF: Phenotypic characterization of human colorectal cancer stem cells. Proc Natl Acad Sci 104: 1015810163, 2007. PMID: 17548814 doi: 10.1073/pnas.0703478104

20 Vermeulen L, Todaro M, de Sousa Mello F, Sprick MR, Kemper K, Alea MP, Richel DJ, Stassi G and Medema JP: Single-cell cloning of colon cancer stem cells reveals a multi-lineage differentiation capacity. Proc Natl Acad Sci 105: 13427-13432, 2008. PMID: 18765800 doi: 10.1073/pnas.0805706105

21 Kanwar SS, Yu Y, Nautiyal J, Patel BB and Majumdar AP: The Wnt/beta-catenin pathway regulates growth and maintenance of colonospheres. Mol Cancer 9: 212-224, 2010. PMID: 20691072 doi: 10.1186/1476-4598-9-212

22 Terasaki M, Maeda H, Miyashita K, Tanaka T, Miyamoto S and Mutoh M: A marine bio-functional lipid, fucoxanthinol, attenuates human colorectal cancer stem-like cell tumorigenicity and sphere formation. J Clin Biochem Nutr 61: 25-32, 2017. PMID: 28751806 doi: 10.3164/jcbn.16-112

23 Medema JP and Vermeulen L: Microenvironmental regulation of stem cells in intestinal homeostasis and cancer. Nature 474: 318326, 2011. PMID: 21677748 doi: 10.1038/nature 10212

24 Mariani F, Sena P and Roncucci L: Inflammatory pathways in the early steps of colorectal cancer development. World J Gastroenterol 20: 9716-9731, 2014. PMID: 25110410 doi: 10.3748/wjg.v20.i29.9716

25 Legitimo A, Consolini R, Failli A, Orsini G and Spisni R: Dendritic cell defects in the colorectal cancer. Hum Vaccin Immunother 10: 3224-3235, 2014. PMID: 25483675 doi: 10.4161/hv.29857

26 Vander Heiden MG, Cantley LC and Thompson CB: Understanding the Warburg effect: the metabolic requirements of cell proliferation. Science 324: 1029-1033. PMID: 19460998 doi: 10.1126/science. 1160809

27 Yoshida M, Hatano N, Nishiumi S, Irino Y, Izumi Y, Takenawa $\mathrm{T}$ and Azuma T: Diagnosis of gastroenterological diseases by metabolome analysis using gas chromatography-mass spectrometry. J Gastroenterol 47: 9-20, 2012. PMID: 22041921 doi: 10.1007/s00535-011-0493-8

28 Dazard, JE, Sandlers Y, Doerner SK, Berger NA and Brunengraber H: Metabolomics of ApcMin/+ mice genetically susceptible to intestinal cancer. BMC Syst Biol 8: 72-92, 2014. PMID: 24954394 doi: 10.1186/1752-0509-8-72

29 Yoshie T, Nishiumi S, Izumi Y, Sakai A, Inoue J, Azuma T and Yoshida M: Regulation of the metabolite profile by an APC gene mutation in colorectal cancer. Cancer Sci 10: 1010-1021, 2012. PMID: 22380946 doi: 10.1111/j.1349-7006.2012.02262.x

30 Terasaki M, Mima M, Kudoh S, Endo T, Maeda H, Hamada J, Osada K, Miyashita K and Mutoh M: Glycine and succinic acid are effective indicators of the suppression of epithelialmesenchymal transition by fucoxanthinol in colorectal cancer stem-like cells. Oncol Rep 40: 412-424, 2018. PMID: 29693702 doi: 10.3892/or.2018.6398 
31 Terasaki M, Matsumoto N, Hashimoto R, Endo T, Maeda H, Hamada J, Osada K, Miyashita K and Mutoh M: Fucoxanthin administration delays occurrence of tumors in xenograft mice by colonospheres, with an anti-tumor predictor of glycine. J Clin Nutr Biochem. In press. doi: https://doi.org/10.3164/jcbn.18-45

32 Center for Experimental Animals: The guidelines for the care and use of laboratory animals. Health Sciences University of Hokkaido (Eds.), Mar 2009.

33 Chen WJ, Ho CC, Chang YL, Chen HY, Lin CA, Ling TY, Yu SL, Yuan SS, Chen YJ, Lin CY, Pan SH, Chou HY, Chen YJ, Chang GC, Chu WC, Lee YM, Lee JY, Lee PJ, Li KC, Chen HW, Yang PC: Cancer-associated fibroblasts regulate the platicity of lung cancer stemness via paracrine signaling. Nat Commun 5: 3472-3488, 2014. PMID: 24668028 doi: 10.1038/ ncomms 4472

34 Kalluri R and Zeisberg M: Fibroblasts in cancer. Nat Rev 6: $392-$ 401, 2006. PMID: 16572188 doi: 10.1038/nrc1877

35 Valencia T, Kim JY, Abu-Baker S, Moscat-Pardos J, Ahn CS, Reina-Campos M, Duran A, Castilla EA, Metallo CM, DiazMeco MT and Moscat J: Metabolic reprogramming of stromal fibroblasts through p62-mTORC1 signaling promotes inflammation and tumorigenesis. Cancer Cell 26: 121-135, 2014. PMID: 25002027 doi: 10.1016/j.ccr.2014.05.004

36 Adegboyega PA, Mifflin RC, DiMari JF, Saada JI and Powell DW: Immunohistochemical study of myofibroblasts in normal colonic mucosa, hyperplastic polyps, and adenomatous colorectal polyps. Arch Pathol Lab Med 126: 829-836, 2002. PMID: 12088453 doi: 10.1043/0003-9985(2002)126<0829: ISOMIN $>2.0 . \mathrm{CO} ; 2$

37 Ikuta D, Miyake T, Shimizu T, Sonoda H, Mukaisho KI, Tokuda A, Ueki T, Sugihara H and Tani M: Fibrosis in metastatic lymph nodes is clinically correlated to poor prognosis in colorectal cancer. Oncotarget 9: 29574-29586, 2018. PMID: 30038705 doi: 10.18632/oncotarget.25636

38 Koliaraki V, Pasparakis M and Kollias G: IKK $\beta$ in intestinal mesenchymal cells promotes initiation of colitis-associated cancer. J Exp Med 212: 2235-2251, 2015. PMID: 26621453 doi: $10.1084 /$ jem.20150542

39 Torres S, Bartolomé RA, Mendes M, Barderas R, FernandezAceñero MJ, Peláez-García A, Peña C, Lopez-Lucendo M, Villar-Vázquez R, de Herreros AG, Bonilla F and Casal JI: Proteome profiling of cancer-associated fibroblasts identifies novel proinflammatory signatures and prognostic markers for colorectal cancer. Clin Cancer Res 19: 6006-6019, 2013. PMID: 24025712 doi: 10.1158/1078-0432.CCR-13-1130

40 Takigawa H, Kitadai Y, Shinagawa K, Yuge R, Higashi Y, Tanaka S, Yasui W and Chayama K: Multikinase inhibitor regorafenib inhibits the growth and metastasis of colon cancer with abundant stroma. Cancer Sci 107: 601-608, 2016. PMID: 26865419 doi: $10.1111 /$ cas. 12907

41 Santos AM, Jung J, Aziz N, Kissil JL and Puré E: Targeting fibroblast activation protein inhibits tumor stromagenesis and growth in mice. J Clin Invest 119: 3613-3625, 2009. PMID: 19920354 doi: $10.1172 /$ JCI38988
42 Guan J, Zhang H, Wen Z, Gu Y, Cheng Y, Sun Y, Zhang T, Jia $\mathrm{C}, \mathrm{Lu} \mathrm{Z}$ and Chen J: Retinoic acid inhibits pancreatic cancer cell migration and EMT through the downregulation of IL-6 in cancer associated fibroblast cells. Cancer Lett 345: 132-139, 2014. PMID: 24334138 doi: 10.1016/j.canlet.2013.12.006

43 Buhrmann C, Kraehe P, Lueders C, Shayan P, Goel A and Shakibaei M: Curcumin suppresses crosstalk between colon cancer stem cells and stromal fibroblasts in the tumor microenvironment: potential role of EMT. PLos One 9: e107514, 2014. PMID: 25238234 doi: 10.1371/journal.pone.0107514

44 Katara GK, Kulshrestha A, Jaiswal MK, Pamarthy S, GilmanSachs A and Beaman KD: Inhibition of vacuolar ATPase subunit in tumor cells delays tumor growth by decreasing the essential macrophage population in the tumor microenvironment. Oncogene 35: 1-58-1065, 2016. PMID: 25961933 doi: 10.1038/ onc.2015.159

45 Steinman RM and Jacques B: Taking dendritic cells into medicine. Nature 449: 419-426, 2007. PMID: 17898760 doi: 10.1038/nature06175

46 Liu J, Zhang N, Li Q, Zhang W, Ke F, Leng Q, Wang H, Chen J and Wang H: Tumor-associated macrophages recruit $\mathrm{CCR}^{+}$ regulatory $\mathrm{T}$ cells and promote the development of colorectal cancer via enhancing CCL20 production in mice. PLos One 6: e19495, 2011. PMID: 21559338 doi: 10.1371/ journal.pone. 0019495

47 Dong R, Gong Y, Meng W, Yuan M, Zhu H, Ying M, He Q, Cao $\mathrm{J}$ and Yang B: The involvement of M2 macrophage polarization inhibition in fenretinide-mediated chemoprevention effects on colon cancer. Cancer Lett 388: 43-53, 2017. PMID: 27913199 doi: 10.1016/j.canlet.2016.11.029

48 Zhao H, Zhang X, Chen X, Li Y, Ke Z, Tang T, Chai H, Guo $\mathrm{AM}$, Chen $\mathrm{H}$ and Yang $\mathrm{J}$ : Isoliquiritigenin, a flavonoid from licorice, blocks M2 macrophage polarization in colitis-associated tumorigenesis through downregulating PGE2 and IL-6. Toxicol Appl Pharmacol 279: 311-321, 2014. PMID: 25026504 doi: 10.1016/j.taap.2014.07.001

49 Iwata-Kajihara $\mathrm{T}$, Sumimoto $\mathrm{H}$, Kawamura $\mathrm{N}$, Ueda $\mathrm{R}$, Takahashi T, Mizuguchi H, Miyagishi M, Takeda K and Kawakami Y: Enhanced cancer immunotherapy using STAT3depleted dendritic cells with high Th1-inducing ability and resistance to cancer cell-derived inhibitory factors. J Immunol 187: 27-36, 2011. PMID: 21632716 doi: 10.4049/ jimmunol. 1002067

50 Sugimoto M, Wong DT, Hirayama A, Soga T and Tomita M: Capillary electrophoresis mass spectrometry-based saliva metabolomics identified oral, breast and pancreatic cancerspecific profiles. Metabolomics 6: 78-95, 2010. PMID: 20300169 doi: 10.1007/s11306-009-0178-y

Received December 15, 2018

Revised January 11, 2018

Accepted January 18, 2019 